\title{
Visual Learning: A Learner Centered Approach to Enhance English Language Teaching
}

\author{
Andrew Philominraj ${ }^{1}$, David Jeyabalan ${ }^{2} \&$ Cristian Vidal-Silva ${ }^{3}$ \\ ${ }^{1}$ Universidad de Talca, Chile \\ ${ }^{2}$ Department of English, Loyola College, Chennai, India \\ ${ }^{3}$ Departamento de Ingeniería Informática, Universidad Autónoma de Chile, Talca, Chile \\ Correspondence: Andrew Philominraj, Programa de Idiomas, Universidad de Talca, Chile. Tel: 56-9-42230670. \\ E-mail: andrew@utalca.cl
}

Received: December 5, 2016

Accepted: February 4, 2017 Online Published: February 6, 2017

doi: 10.5539/elt.v10n3p54

URL: http://doi.org/10.5539/elt.v10n3p54

\begin{abstract}
This article presents an empirical study carried out among the students of higher secondary schools to find out how English language learning occurs naturally in an environment where learners are encouraged by an appropriate method such as visual learning. The primary data was collected from 504 students with different pretested questionnaires. A selection of a series of variables is taken into consideration in the survey, which is measured and information of each one is collected to describe what is researched. The results indicate that visual learning is an essential part of the overall experience that the learners gain towards their process of language learning. Also, it constitutes a vital process of 'Input and Interaction' for the learner ensuring that his needs, necessities and aspirations are taken into account and by making him involved, produce genuine learning.
\end{abstract}

Keywords: English, language, visual learning, images, learning style

\section{Introduction}

English plays an important role and occupies a unique position in India. English holds a high visibility throughout India. This is mostly because English print invades life at all levels, starting from shop sign boards in urban and rural areas to consumer packaging of all commonly used commodities, to national newspapers and popular magazines (Baruah, 1991). English also occupies a great deal of space on the airwaves, in the form of TV and radio programmes. The world outside the English classroom in India is therefore an invaluable source of real, live English in use. This importance of English language has made every citizen to seek 'social empowerment' (Kachru, 1983) in order to gain his or her ways to economic development. This economic development comes with Education and very specially language education, which is the key to open doors in job markets and help a common person find his or her place in the society. English is taught as a subject, and is also a medium of instruction in schools and colleges in India, but experiences show that learners at all levels fail to stand up to the international standards of language communication. Several studies show that practices used in the teaching and learning of English are still far from helping learners achieve their domain in the English language communication. In the report of the Education First (EF, 2016) that released the English proficiency index, India stands in position 22 out of 72 analysed countries. This is far below in comparison with countries such as Hungary, Serbia and Argentina where second or foreign language has never been English unlike India. Given the universe of the learners, and also the outstanding role of English, it becomes important to look into ways of making this language learning experience more alluring and motivating for the students to develop a liking and thus make their language learning experience not only successful but also more interesting. This article is an empirical study carried out among a group of students, in several schools, in the city of Chennai, to explore the importance and the use of Visual learning, as one such appealing method based on Learner Centered Approach to the learning of English as a second language.

\section{Visual Learning}

Visual learning is one of the "most exciting and stimulating method" (Baratta, 2010). Kant recognizes the importance of 'vision and thinking' and states that there is no separation between these two. They are of one process. Visual learning is the ability to structure, organize and give meaning to visible items. The skill of 
reading the written language is an example of a highly specialized visual skill. "Many media and many styles of visual presentation are useful to the language learners. That is to say, all audio-visual materials have positive contributions to language learning as long as they are used at right time, in the right place" (Wright, 1976; Cakir, 2006). In language learning and teaching process, learner uses his eyes as well as his ears; but his eyes are basic in learning. (Rivers, 1981; Cakir, 2006) claim that "it clearly contributes to the understanding of another culture by providing vicarious contact with speakers of the language, through both audio and visual means".

Visual learning is a teaching and learning style in which ideas, concepts, data and other information are associated with images and techniques. "Visual learning is the major transmitter of our cultural heritage second only to the spoken word" (Sless, 1981). Visual learning refers to the process through which learners gain knowledge and understanding explicitly through, visual tools that include, printed words, paintings, drawings, sculpture, photography, cartography, diagrams, video, television, graphs, charts, images, films, newspapers, signs, slides etc. These tools help in delivering educational content more effectively. They greatly benefit and enhance the learning process as interactive effects and are used to reinforce the material being studied. Visual learning is a great way of learning, as it aids to increase a learner's interest in a certain subject, makes the learning process more enjoyable and sustains the learners' interest for longer periods.

Doff (1988) summarizes the following on Visual learning very eloquently saying:

Visual aids include pictures, objects, and things for the learners to look and talk about. Visual aids are important because showing visuals focuses attention on meaning and helps to make the language in the class more real and alive; having something to look at keeps the learner's attention, and makes the class more interesting. Visuals can be used at any stage of the lesson, to help in presenting new language or introducing a topic, as part of language practice, and when reviewing language that has been presented earlier; good visual aids can be used repeatedly and shared by different teachers.

Learning for visual learners takes place all at once, with large chunks of information grasped in intuitive leaps, rather than in the gradual accumulation of isolated facts, small steps or habit patterns gained through practice. Schramm (1977) is of the idea that "learners can effectively learn from the media, from any medium, and at times much better than the classroom teaching itself". Visual learning attracts almost the entire concentration of the individual since it makes learning process more interesting and gives the learner a new experience and finally results in an effective communication of the language. Message in visual learning is treated as a separate entity. Having the message as the key in visual learning means, a relationship that is constructed between the subject and the object. This means that it is author-message relationship and as well the audience-message relationship.

The power of media has strongly influenced education. The general findings are that "the educators are woefully ignorant of their learners" (Golding, 1974; Schlesinger, 1978). This is due to structural and traditional set up and the result is a great wall between the content and the needs of the learners. Education, according to David Sless (1981) becomes uninteresting when the learners are denied with their rights of questioning and interaction. Creating an impact is the ultimate aim of Visual learning and if this could find its way in the educational programme then there could be a new way for a successful teaching and learning method.

\section{Developments of Visual Learning}

The Bauhaus Basic Design Course was a source of inspiration that has played an important role in the stylistic development of visual practices in the twentieth century. It provides a coherent pedagogical programme based on what looks like a scientific basis, and most importantly, it is used as the basic introductory course in most of the colleges of art, in the field of visual communication and learning. This Course can be seen as an important contribution to great many practices in contemporary visual communication. The legitimation of this Course and its pedagogic implication were sustained by two theories such as; Gestalt Theory from Psychology and Relativity Theory of Physics. The relevance of the results had made Kepes, a generation earlier, to declare the universality of Visual learning. He is of the conviction that visual language disseminates knowledge than any other vehicle of communication. By means of visual communication, learners are capable of expressing and relaying their experience in object form. "Visual communication is universal and international: it knows no limits of tongue, vocabulary, or grammar, and it can be perceived by the illiterate as well as the literate. Visual language can convey facts and ideas in a wider and deeper range than almost any other means of communication" (Kepes, 1995).

The acquisition of language involves far more than just the rules of naming, and the recognition of objects in pictures. Pictures are not normally the sort of objects in which one would care to exercise his or her intelligence. Any tool used for communication plays a particularly important role because they shape the nature of the learners' individuality. This individuality of learners is an essential element to be considered in language learning. 
When learners are introduced into the world of images, spontaneous creativity towards the goal is achieved. "Words are associated with thinking but pictures are associated with seeing; one is an intellectual activity, the other purely sensory and therefore simply a matter of picking up the information which is there" (Sless, 1981).

Sless in his explanation of visual learning using the tool of picture comments that there is no equivalent for picturing in language education. Pictureable material is generally easier to learn and remember than less pictureable material. Specifically, pictures are generally more concrete and memorable than words. High imagery words in particular are more memorable than abstract, low-imagery words. The generalisation for linguistic material extends to phrases, sentences and paragraphs. "At all levels, memorability is directly related to the pictureabilty or image-arousing value of the materials" (Paivio, 1971). Sadoski and Paivio (2013) found that "the imagery value of conceptual categories as well as instructions to use visual imagery during learning facilitated the acquisition of concepts". The knowledge about learners' expectations is an essential part of learners' understanding of the audience - message relation. It is so because extending and developing the use of pictorial material in education does not mean exposing learners to more of it, but help change learners' expectations so that they are prepared to take the best advantage of what is offered in the environment. "Through much exposure to pictures, learners not only become 'literate' in reading pictures but in the process their ways of thinking be modified" (Fleming, 1979).

There are several techniques to teach English through pictures. One such technique, that revealed by research the value of imagery, is mnemonic technique, in which learners are instructed to use imagery in order to remember items. "Experimental studies have established that such techniques are highly effective" (Paivio, 1971) and many experiments have provided information on the precise role of visual memory processes in the effects. These mnemonic techniques and the processes involved in visual learning are particularly relevant here because they draw on the learners' long-term visual memory and thus sustain knowledge. Picture contributes to interest and motivation; it creates a sense of the context of the language, and also acts as a specific reference point or an impetus. Verbal language is only a part through which meaning is taken from context but what is seen plays an enormous part in affecting the learner by providing information. One predicts, deduces, and infers not only from what one hears and reads but from what one sees around and also from remembering those that had been seen. "Picture as a tool of visual learning is not just as an aspect of method but through their representation of places, object and people constitute an essential part of the overall experience in learning to which learners are expected to be exposed" (Wright, 1989).

Visual learning introduces an array of spectacle for the learners to their process of learning. Visual aids are a trap for learners' gaze, representations of knowledge and the "lessons learnt from visual culture affirm the central place of subjectivities" (Doy, 2005) and the means to greatly benefit and enhance learning. In teaching and learning, visual learning is an ongoing process with two foci, "the author-message and the audience-message, where each functions within a framework of assumptions and expectations" (Sless, 1981). "They represent two worlds in which the only unconditional similarities are the physical form of the message and the humanity of the learners" (Sless, 1981). Different concepts of learning spring from different epistemological frameworks but the idea that remains beneath is the nature of knowledge. This makes sure that every learner has an equal opportunity to use his or her individual talents to the fullest degree to achieve language learning. Thus, Visual learning is more effective, communicative and interesting to the teaching and learning of English language.

\section{Methodology and Analysis of Data}

As a corollary to the theoretical understanding of the present topic, an empirical study by way of data collection, analysis and interpretation has been carried out in order to substantiate the proposal and the province of the present study. The primary data was collected from 504 students with different pretested questionnaires. The survey was conducted in ten higher secondary schools in the city of Chennai. A selection of a series of variables is taken into consideration in the survey, which is measured, and information on each one is collected to describe what is researched (Hernandez et al., 2003). The survey questions for students contained topics concerning their exposure to environment and visual and audiovisual tools. All the questions were of closed-ended model, allowing learners to choose one of the alternatives. The statistical analysis and the results of every question to the learners are presented through individual tables and for the purpose of the diagrammatical representation a few questions are clubbed wherever it is necessary and represented through charts. The analysis and the results of the data of the survey are also followed with their interpretations. 
Table 1. Sample learners on listening to English songs

\begin{tabular}{llllll}
\hline Sl.No & Opinion & Frequency & Percent & Valid Percent & Cumulative Percent \\
\hline 1 & Always & 284 & 56.3 & 56.3 & 56.3 \\
2 & Often & 150 & 29.8 & 29.8 & 86.1 \\
3 & Rare & 55 & 10.9 & 10.9 & 97.0 \\
4 & Never & 6 & 1.2 & 1.2 & 98.2 \\
5 & No opinión & 9 & 1.8 & 1.8 & 100.0 \\
& Total & 504 & 100.0 & 100.0 & \\
\hline
\end{tabular}

Source: Computed from field survey.

56.3 percent of the sample learners, as shown in table 1, have opined that they have listened to English songs as always, followed by 29.8 percent as often and 10.9 percent as rare. Among the sample learners' the majority of them listening to English songs is a clear indication of the learners using visual tools to the learning of English language.

Table 2. Sample learners on watching English movies

\begin{tabular}{llllll}
\hline Sl.No & Opinion & Frequency & Percent & Valid Percent & Cumulative Percent \\
\hline 1 & Always & 271 & 53.8 & 53.8 & 53.8 \\
2 & Often & 143 & 28.4 & 28.4 & 82.2 \\
3 & Rare & 60 & 11.9 & 11.9 & 94.1 \\
4 & Never & 21 & 4.2 & 4.2 & 98.3 \\
5 & No opinion & 9 & 1.7 & 1.7 & 100.0 \\
& Total & 504 & 100.0 & 100.0 & \\
\hline
\end{tabular}

Source: Computed from field survey.

Table 2 reveals that 53.8 percent have opined as always, followed by 28.4 percent as often and 11.9 percent as rare on their response to the question on watching English movies for learning English. A total of 82.2 percent of the sample learners' watching English movies is a positive confirmation of the learners' interest in using visual tools to improve their knowledge of English language.

Table 3. Sample learners on watching English news channels

\begin{tabular}{llllll}
\hline Sl.No & Opinion & Frequency & Percent & Valid Percent & Cumulative Percent \\
\hline 1 & Always & 224 & 44.4 & 44.4 & 44.4 \\
2 & Often & 156 & 31.0 & 31.0 & 75.4 \\
3 & Rare & 92 & 18.3 & 18.3 & 93.7 \\
4 & Never & 25 & 5.0 & 5.0 & 98.6 \\
5 & No opinion & 7 & 1.4 & 1.4 & 100.0 \\
& Total & 504 & 100.0 & 100.0 & \\
\hline
\end{tabular}

Source: Computed from field survey.

Table 3 depicts that a 44.4 percent of sample learners have opined as always, 31 percent opined as often and 18.3 percent as rare, in watching English news channels. A total of 75.4 percent of the sample learners listening to English news channels is a clear sign of learners' preference for visual tools to improve their knowledge of English. 


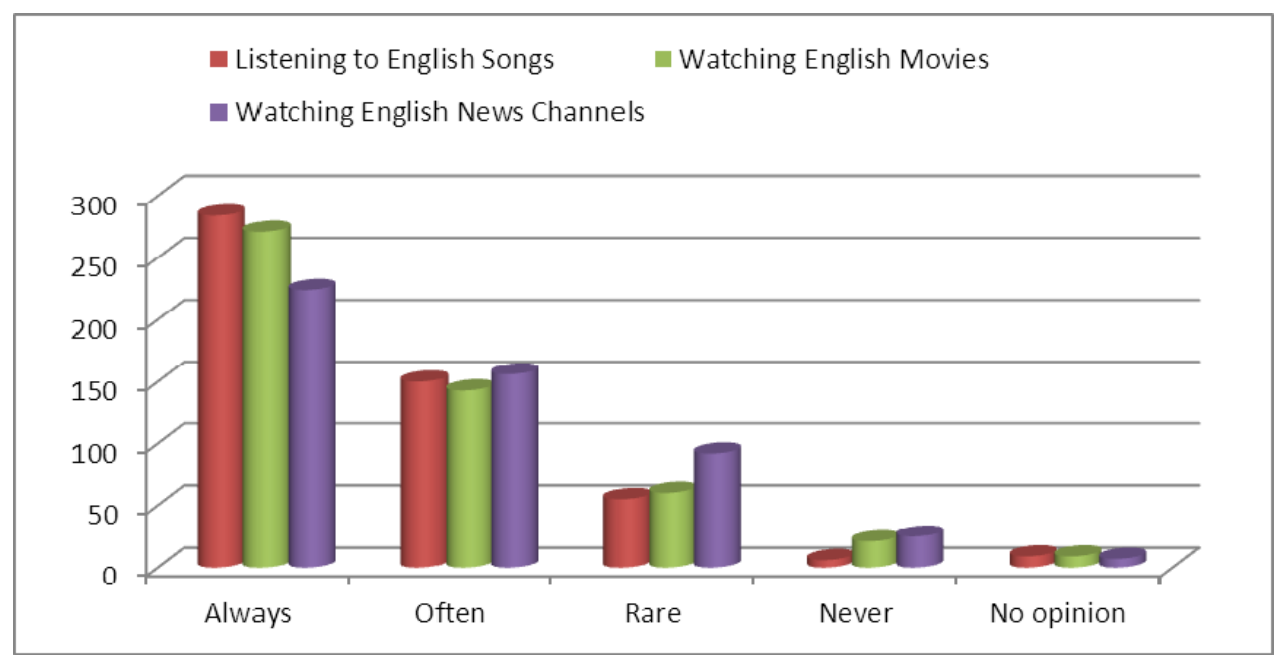

Chart 1. Sample learners on using visual aids to learn English

Source: Based on Table 1, 2, 3 .

Table 4. Sample learners on reading English newspapers and magazines

\begin{tabular}{llllll}
\hline Sl.No & Opinion & Frequency & Percent & Valid Percent & Cumulative Percent \\
\hline 1 & Always & 227 & 45.0 & 45.0 & 45.0 \\
2 & Often & 172 & 34.1 & 34.1 & 79.1 \\
3 & Rare & 85 & 16.9 & 16.9 & 96.0 \\
4 & Never & 15 & 3.0 & 3.0 & 99.0 \\
5 & No opinion & 5 & 1.0 & 1.0 & 100.0 \\
& Total & 504 & 100.0 & 100.0 & \\
\hline
\end{tabular}

Source: Computed from field survey.

Table 4 shows that 45 percent have opined as always, 34.1 percent opined as often, 16.9 percent said as rare and 3 percent have said never in reading English newspapers and magazines in the study area. The reading habit as expressed by 79.1 percent of the sample learners' is very much encouraging due to the option exhibited by them not only to read newspapers and magazines but also to read them in English. It is a clear sign of learners' inclination to opt for visual tools in the learning of the English language.

Table 5. Sample learners on reading English aloud

\begin{tabular}{llllll}
\hline S1.No & Opinion & Frequency & Percent & Valid Percent & Cumulative Percent \\
\hline 1 & Always & 170 & 33.7 & 33.7 & 33.7 \\
2 & Often & 174 & 34.5 & 34.5 & 68.3 \\
3 & Rare & 102 & 20.2 & 20.2 & 88.5 \\
4 & Never & 48 & 9.5 & 9.5 & 98.0 \\
5 & No opinión & 10 & 2.0 & 2.0 & 100.0 \\
& Total & 504 & 100.0 & 100.0 & \\
\hline
\end{tabular}

Source: Computed from field survey.

Table 5 projects that 33.7 percent have opined as always, 34.5 percent opined as often, 20.2 percent said rare and 9.2 percent have said never for reading aloud in English. From this, it is evident that 69.3 percent (always and often) of sample learners use visual aids and signboards either in class or in the learning environment that serve 
as "comprehensible input" to read English aloud that accentuates the learning of English language.

Table 6. Sample learners on learning English by watching TV

\begin{tabular}{llllll}
\hline S1.No & Opinion & Frequency & Percent & Valid Percent & Cumulative Percent \\
\hline 1 & Always & 197 & 39.1 & 39.1 & 39.1 \\
2 & Often & 178 & 35.3 & 35.3 & 74.4 \\
3 & Rare & 84 & 16.7 & 16.7 & 91.1 \\
4 & Never & 35 & 6.9 & 6.9 & 98.0 \\
5 & No opinion & 10 & 2.0 & 2.0 & 100.0 \\
& Total & 504 & 100.0 & 100.0 & \\
\hline
\end{tabular}

Source: Computed from field survey.

To the question on learning English by watching T.V, 39.1 percent of the sample learners have expressed as always, while 35.3 percent as often followed by 16.7 percent as rare and 6.9 percent have said never.74.4 percent (always and often) of respondents have opined in the positive in watching TV programmes to learn English. Visual tools used for learning confirm that Visual learning is one optimal method preferred by learners to strengthen their language competence.

Table 7. Sample learners on reading transit advertisement in English

\begin{tabular}{llllll}
\hline Sl.No & Opinion & Frequency & Percent & Valid Percent & Cumulative Percent \\
\hline 1 & Always & 307 & 60.9 & 60.9 & 60.9 \\
2 & Often & 134 & 26.6 & 26.6 & 87.5 \\
3 & Rare & 47 & 9.3 & 9.3 & 96.8 \\
4 & Never & 13 & 2.6 & 2.6 & 99.4 \\
5 & No opinión & 3 & .6 & .6 & 100.0 \\
& Total & 504 & 100.0 & 100.0 & \\
\hline
\end{tabular}

Source: Computed from field survey.

Reading flex/posters/ads written in English in public places is opined as always by 60.9 percent, as often by 26.6 percent, as rare by 9.3 percent and never by 2.6 percent of the sample learners. The majority $(87.5$ percent combining always and often) of the sample learners are able to read the flex/posters/ads written in English is an indicator of their English language proficiency. This data, at the same time also confirms the continuous interest to strengthen their language through means of visual aids presented in the environment as observed from the previous tables.

Table 8. Sample learners on reading advertisements shown on TV

\begin{tabular}{llllll}
\hline S1.No & Opinion & Frequency & Percent & Valid Percent & Cumulative Percent \\
\hline 1 & Always & 302 & 59.9 & 59.9 & 59.9 \\
2 & Often & 150 & 29.8 & 29.8 & 89.7 \\
3 & Rare & 41 & 8.1 & 8.1 & 97.8 \\
4 & Never & 8 & 1.6 & 1.6 & 99.4 \\
5 & No opinión & 3 & .6 & .6 & 100.0 \\
& Total & 504 & 100.0 & 100.0 & \\
\hline
\end{tabular}

Source: Computed from field survey. 
Table 8 exhibits that 59.9 percent have opined as always, 29.8 percent opined as often, 8.1 percent have said as rare and 1.6 percent have said never for reading advertisements or captions shown on TV in English. Here again the majority ( 89.7 percent combining the responses of always and often) of the sample learners confirm their preference in using visual aids like TV for learning English language.

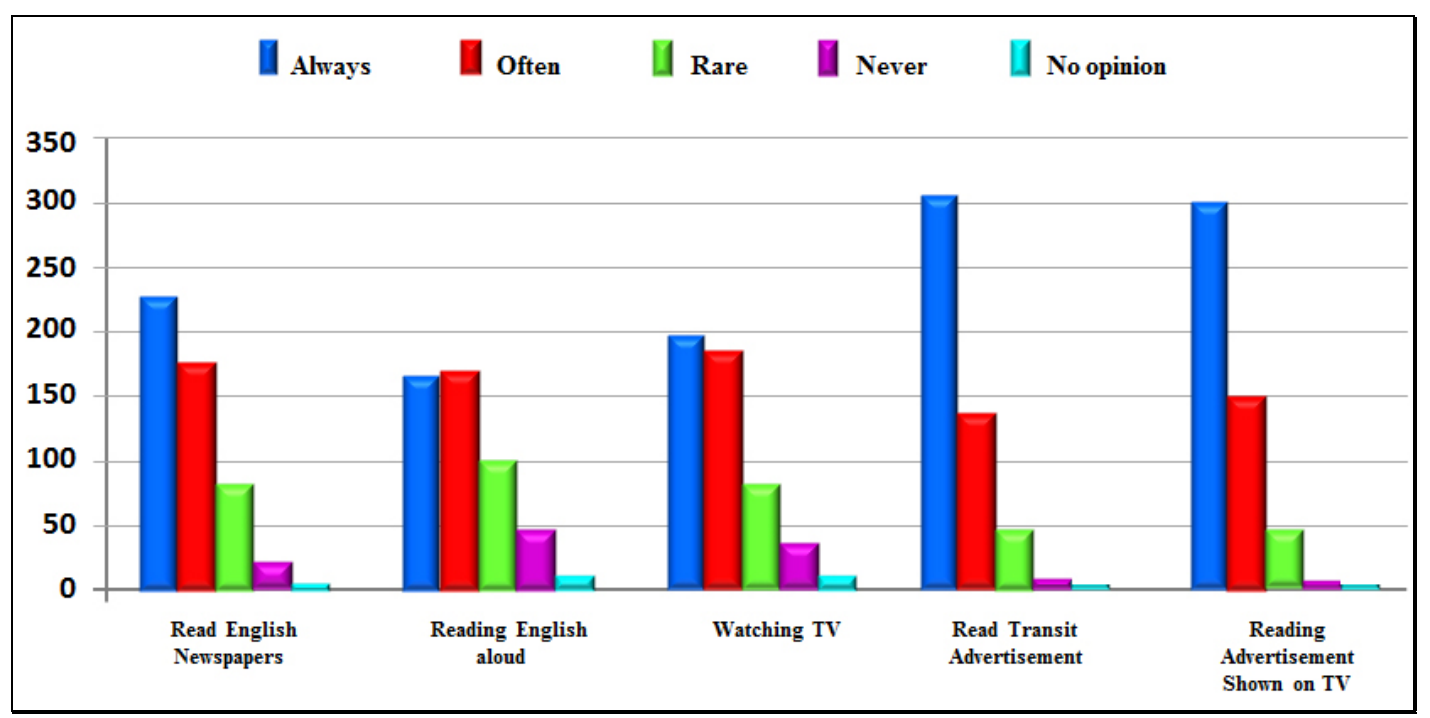

Chart 2. Learners' preference for using visual aids

Table 9. Sample learners on visual learning practices of their English lessons

\begin{tabular}{llllll}
\hline Sl.No & Opinion & Frequency & Percent & Valid Percent & Cumulative Percent \\
\hline 1 & Flash card & 92 & 18.3 & 18.3 & 18.3 \\
2 & T.V/Video & 61 & 12.1 & 12.1 & 30.4 \\
3 & Films /Slides & 35 & 6.9 & 6.9 & 37.3 \\
4 & Newspapers/ magazines & 46 & 9.1 & 9.1 & 46.4 \\
5 & Lab experiment & 52 & 10.3 & 10.3 & 56.7 \\
6 & Signboards & 29 & 5.8 & 5.8 & 62.5 \\
7 & Charts & 42 & 8.3 & 8.3 & 70.8 \\
8 & ICT-Smart board & 87 & 17.3 & 17.3 & 88.1 \\
9 & Diagrams & 36 & 7.1 & 7.1 & 95.2 \\
10 & Flow charts & 24 & 4.8 & 4.8 & 100.0 \\
& Total & 504 & 100.0 & 100.0 & \\
\hline
\end{tabular}

Source: Computed from field survey.

Table 9 gives the opinion of sample learners' on visual learning i.e., flash card, TV/video, films/slides, newspapers/magazines, lab experiment, signboards, charts, ICT-smart board, diagrams and flow charts. Use of objects, pictures, visual tools attaches more importance to learners' language learning as it results in giving a large amount of language input. The preference of sample learners to flash card (18.3 percent) and ICT-Smart board (17.3 percent) indicates the importance of vision in language learning. These visual tools help to capture the attention and sustain the learners' interest for longer periods. 


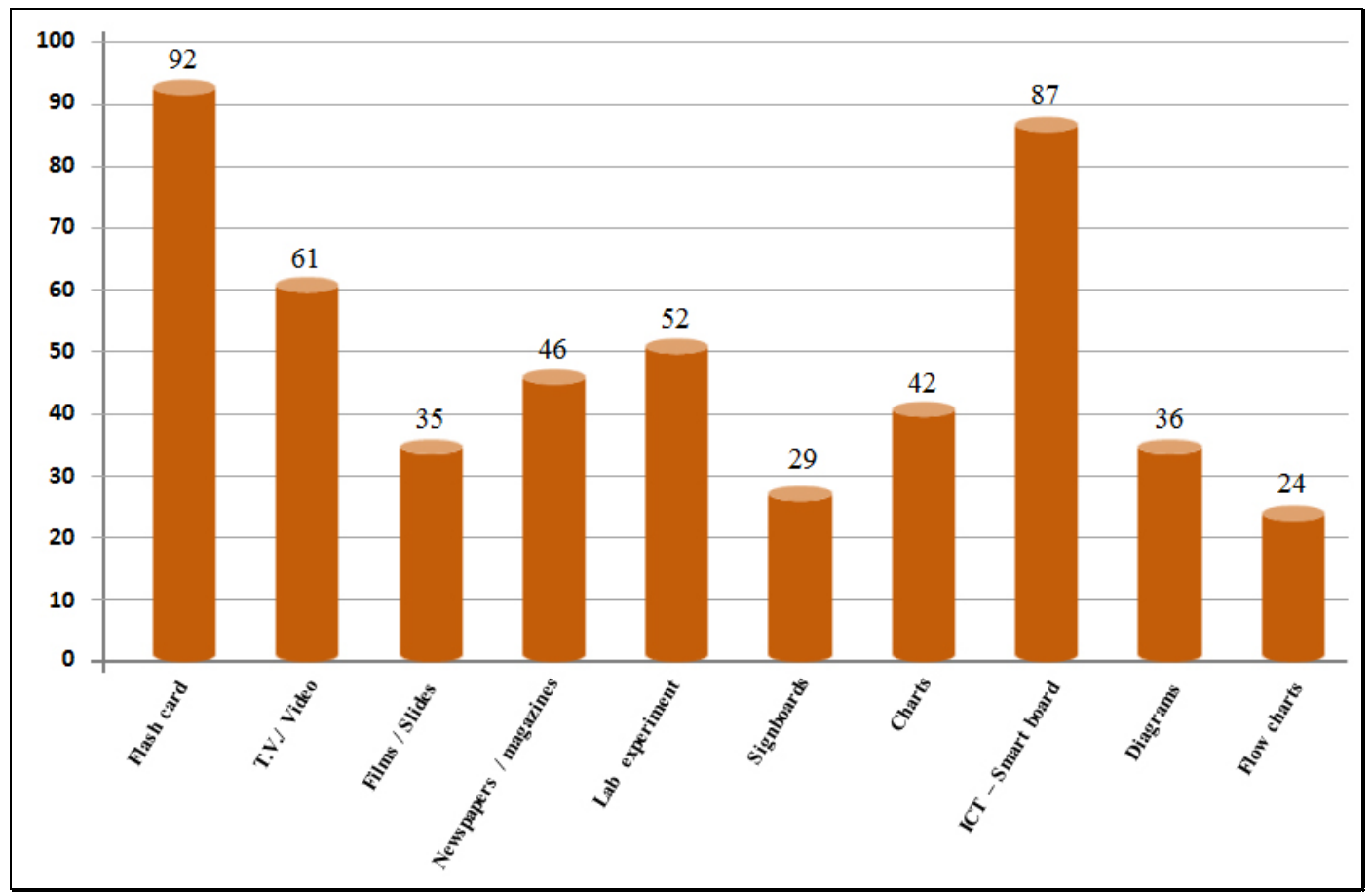

Chart 3. Sample learners on visual learning practices of their English lessons

Source: Based on Table 9.

\section{Conclusion}

The empirical study on exploring the importance and the use of visual learning amidst students in the city of Chennai clearly indicates that teaching here is no longer the "taking up of the predetermined problem in a ritually defined setting" (Illich, 1970). Results from learners' survey throw light on the fact that learning situation has to be creative and exploratory. Learners' interest has been on sharing knowledge through skill exchanges, with the teacher, and the environment. Learning is not divorced from living; the outside world is not made to disappear from the classroom. Learners are open to access the available resources and also make themselves to be introduced and exposed to any help that is available. Results gathered from the survey confirms that learners experience do not limit itself to classroom but goes beyond, facilitating thus the content in becoming "Input" and favoring "Interaction" in this process of learning the language.

The survey also reveals that by using visual learning learners are exposed to the natural setup of the environment and the media, which constitute as vital elements in gaining interest, maintaining attention and helping the learner to grasp the gist of the language. The display of everything that is visual plays an enormous part in affecting the learners and giving learners' information. Learners predict, deduce and infer not only from what they hear and read but what they see around them and from what they remember having seen. Visual aid for the learners is not just an aspect of method, but through representation of places, objects and people it forms an essential part of the overall experience that the learners gain towards their process of language learning.

\section{References}

Barrata, A. (2010). Visual Writing. UK; Cambridge Scholar Publishing.

Baruah, T. C. (1991). The English teachers' handbook, New Delhi. Sterling Publishers Pvt Ltd.

Cakir, I. (2006). The use of video as an audio-visual material in foreign language teaching classroom. The Turkish Online Journal of Educational Technology, 5(4). Retrieved December 26, 2016 from http://tojnet.net/articles/v5i4/549.pdf

Doff, A. (1988). Teach English - A training course for teachers. Cambridge: Cambridge University Press.

Doy. G. (2005). Picture the self. Changing views of the subject in visual culture. London: IB Tauris and Co Ltd.

Education First. (2016). Informe índice de nivel de Inglés. Retrieved December 26, 2016 from http://www.ef.cl

Fleming, M. L. (1979). On pictures in educational research. Instructional Science, 8, 235-251. 
https://doi.org/10.1007/BF00055242

Golding, P. (1974). The mass media. London: Longmans.

Hernández et al. (2003). Metodología de la investigación. Editorial McG.

Illich, I. (1970). Deschooling society. London: Calder \& Boyars Ltd.

Kachru, B. B. (1983). The indianization of English: The English language in India. Oxford: Oxford University Press.

Kepes, G. (1995). Language of vision. New York, Dover Publications, INC.

Paivio, A. (1971). Imagery and verbal processes. NewYork: Holt.

Rivers, W. M. (1981). Teaching foreign language skills. Chicago: Univ. of Chicago Press.

Sadoski, M., \& Paivio, A. (2013). Imagery and Text: A Dual Coding Theory of Reading and Writing (2nd Ed) Routledge.

Schlesinger, P. (1978). Putting reality together. London: Constable.

Schramm, W. (1977). Big media, little media: Tools and technologies for instruction. Beverly Hills, California: Sage Publications.

Sless, D. (1981). Learning and visual communication. London: Croom Helm London.

Wright, A. (1976). Visual materials for language teachers. London: Longman.

Wright, A. (1989). Pictures for language learning. Cambridge: Cambridge University Press.

\section{Copyrights}

Copyright for this article is retained by the author(s), with first publication rights granted to the journal.

This is an open-access article distributed under the terms and conditions of the Creative Commons Attribution license (http://creativecommons.org/licenses/by/4.0/). 